\title{
Slams e espaços educacionais extraescolares
}

Danielle Marcia Hachmann de Lacerda da Gama ${ }^{1}$, Diogo Linhares Fernandes ${ }^{2}$

\begin{abstract}
Resumo
Partindo da compreensão sobre o papel que uma educação emancipadora pode cumprir para a juventude, ao ter na sua formação os próprios atores sociais envolvidos e atuando de forma crítica, e considerando os limites que a educação formal pode apresentar à formação de jovens estudantes, buscamos neste artigo fazer uma reflexão sobre a atuação dos jovens, em sua maioria moradores das periferias urbanas, que vêm construindo espaços expressivos como as batalhas de poesia conhecidas como slams. Nelas, seus atores veiculam poemas que falam sobre as experiências vividas e que, em geral, dizem respeito a diversas formas de marginalização e opressão a que estão sujeitos por suas origens territoriais ou identitárias. Há nas batalhas uma intenção de promover o debate e conscientização dos sujeitos participantes a respeito de questões sociais, em um modo de aprender sobre si, sobre seu espaço, seus direitos. Apoiamos nossa reflexão em revisão bibliográfica, ilustrando-a com o caso dos Slams das Minas, circuito de batalhas promovidas por jovens mulheres. Consideramos que os slams podem ser pensados como espaços de educação popular, não formal, capazes de contribuir na formação social e humana dos sujeitos que deles participam.
\end{abstract}

\section{Palavras-chave}

Slam. Educação. Juventude.

1 Mestra em Ciências Sociais pela Universidade Federal do Recôncavo da Bahia, Brasil. E-mail: dani.dagama@hotmail.com.

2 Mestrando em Antropologia na Universidade Federal da Bahia, Brasil. E-mail: dlinhares.fernandes@gmail.com. 


\title{
Slams and extra-schooling educational spaces
}

Danielle Marcia Hachmann de Lacerda da Gama ${ }^{3}$, Diogo Linhares Fernandes ${ }^{4}$

\begin{abstract}
Assuming the comprehension of the role of an emancipating education for youth, by having in its formation the social actors themselves, engaged and acting critically, and considering the limits that the formal education may present to the formation of young students, we aim, in the present essay, to launch a reflection about the acting of young people, for the most part inhabitants of urban outskirts, that have been building expressive spaces as the poetry battles known as slams. In these battles, its actors vehicle poems that speak about the experiences that they live and that, in general, tell about the various forms of marginalization and oppression to which they are subject for their territorial or identitary origins. There is an intention, in the battles, of promoting the debate and awareness, of those subjects participating, about social issues, in a way of learning about oneself, about their space, their rights. We support our reflection on bibliographic review, illustrating it with the case of the Slams das Minas [Gal's Slams, in free translation], a circuit of battles promoted by young women. We consider that slams can be thought as spaces of popular non-formal education, able to contribute in the social and human formation of the subjects that participate of them.
\end{abstract}

\section{Keywords}

Slam. Education. Youth.

3 Master in Social Sciences, Federal University of Recôncavo da Bahia, State of Bahia, Brazil. E-mail: dani.dagama@hotmail.com.

4 Master degree student in Anthropology, Federal University of Bahia, State of Bahia, Brazil. E-mail: dlinhares.fernandes@gmail.com. 


\section{Introdução}

O presente artigo propõe uma reflexão sobre as batalhas de poesia, conhecidas como slams, como ações de formação educativa não formal popular, partindo de uma compreensão sobre a importância de se superarem limites que a instituição escolar pode apresentar para o aprendizado e vivência de jovens estudantes. Pensamos as manifestações de poesia que acontecem em espaços públicos, como ruas e praças, geralmente em locais periféricos das cidades, como momentos de grande potencial educativo, em seu aspecto mais amplo, ou seja, que podem contribuir para a formação de indivíduos que participam desses espaços, na participação ou construção do evento.

Nas batalhas são apresentados poemas que tratam de temas diversos, mas que têm sido voltados a discutir questões sociais - como racismo, machismo e LGBTQfobia - ou questões políticas. Os jovens que estão primordialmente à frente da produção das batalhas e formadores de sua audiência são provenientes das camadas populares das periferias de grandes centros urbanos, em sua maioria negros e, entre eles, mulheres e membros da comunidade LGBTQ+, que buscam provocar no público a reflexão sobre temas que consideram relevantes e que muitas vezes dizem respeito às suas próprias condições de existência, em uma sociedade que lhes marginaliza e exclui. O debate de tais temas em eventos públicos de poesia promove momentos de fala e escuta e serve à formação social e humana desses sujeitos, cujo aprendizado é potencializado, ainda, pela vivência relacional entre os participantes.

Essa reflexão nos surge com a provocação de perceber a escola como uma instituição formal que está frente a limitações sobre como envolver e cativar os jovens estudantes. $\mathrm{O}$ espaço escolar demonstra nesses limites a dificuldade em tornar a escola um ambiente lúdico, acolhedor, sensível, onde os estudantes sintam a capacidade de estar incluídos em seu contexto. Ao mesmo tempo, é um espaço amplo, diverso, que tem em seu corpo estudantil jovens que também se encontram ativos em manifestações artísticas fora do espaço escolar, que se envolvem na poesia e que também conseguem fazer desse espaço exterior um local de formação social, cultural e política capaz de fortalecer um longo processo de construção como sujeitos sociais críticos.

Essa formação social crítica pode contribuir com o próprio processo formativo dentro das escolas, a partir do reconhecimento do espaço da rua como um local de liberdade para discutir diferentes temas materializados nas batalhas de poesia. Consideramos que os jovens 
que frequentam as escolas chegam a essas instituições marcados pela diversidade, fruto das suas relações sociais anteriores ou paralelas à escola (DAYRELL, 1996).

Para compreender melhor estes processos, apresentaremos nossa reflexão baseada em pesquisa bibliográfica, ilustrando nossas reflexões com o caso dos Slams das Minas, circuito de batalhas de poesias de jovens mulheres que tem sido promovido em vários pontos do país. Para analisar a potencialidade do slam no campo da educação não formal, voltamos nosso olhar para a instituição escolar como nos aponta Dayrell (1996) no que se refere à homogeneização dos sujeitos como alunos, assim como à homogeneização da escola como algo universalizado, o que faz com que seu espaço seja construído como único, e os conhecimentos passem a ser enxergados como coisas e objetos, dificultando que o processo de ensinar e aprender seja construído de forma compartilhada e com respeito à diversidade.

\section{Slam: batalhas de poesia}

Nas últimas décadas, em especial a partir dos anos 2000, intervenções e movimentos artístico-culturais, promovidos em comunidades de periferias em grandes cidades, vêm conseguindo solidificar cenários de visibilidade e de escuta do indivíduo desses locais. Entre essas ações está a criação, em 2001, do Sarau da Cooperifa, pelo poeta Sergio Vaz, e do Sarau do Binho, ambos da zona sul de São Paulo. Ao lado dessas intervenções, podemos citar livros produzidos a partir da perspectiva das periferias, como é o caso de Capão Pecado, de Ferréz, que expôs o cotidiano de Capão Redondo, também região da periferia paulistana, e Cabeça de Porco, escrito pelo antropólogo Luiz Eduardo Soares, o ativista Celso Athayde e o rapper MV Bill. Também assinalamos aqui a fundação, em 2009, do projeto de extensão "Universidade das Quebradas", no Rio de Janeiro, vinculado à Universidade Federal do Rio de Janeiro (UFRJ) com o objetivo de promover a troca de saberes e conhecimentos entre academia e produtores culturais das periferias.

Em especial os saraus, como eventos abertos ao público e um chamado à "democratização da poesia", se multiplicaram por periferias de todo o país. A existência de saraus "marginais", mais além da apropriação de um costume de origem elitista, popularizando a arte poética, configura oportunidade de compartilhamento de experiências relevantes para esses públicos, e de criação de laços em momentos de fala e escuta em que tais experiências podem ser publicadas e postas em comum. 
Fortaleceu-se o papel do artista da periferia em relação a sua comunidade, e do indivíduo em relação à arte - seja como produtor ou espectador de intervenções, esse sujeito passa a enxergar nos eventos literários uma ação política, até mesmo pedagógica. Para Hollanda (2005, não paginado), a "própria noção de cultura, e por tabela a de literatura, é forçada a repensar sua função social”. A autora afirma, ainda, que os saraus passaram a ter funções como: "formação de leitores, divulgação da literatura, estímulo à criação e à educação, letramento, empoderamento social, socialização em torno da cultura". As comunidades reiteravam seu direito à arte, sua fruição e produção.

Com o sólido papel político dos saraus, muitas vezes ligados a eventos da cultura hiphop, como batalhas de rap, uma nova forma de performance artística atingiu em cheio o gosto desse público: os slams, batalhas de poesia falada realizadas em locais públicos, em especial em periferias da cidade.

Slam é uma onomatopeia que representa a batida de uma porta com o vento forte. Mas pelo dicionário de Cambridge encontramos sua definição como um "evento no qual pessoas leem seus poemas para serem julgados por uma audiência" (tradução nossa). Os eventos em que autores competem com suas composições poéticas originaram-se em fins da década de 1980, em Chicago, nos Estado Unidos. Mark Smith, um operário da construção civil e poeta, com o grupo Chicago Poetry Ensemble, criou as primeiras noites de performances de poesia, dando-lhes o nome de slam poetry. Segundo D'Alva (2011, p. 120), era uma “tentativa de popularização da poesia falada em contraponto aos fechados e assépticos circuitos acadêmicos". No Brasil, onde slams acontecem desde 2008, as batalhas têm sido em especial apropriadas pelas periferias como espaços para discussão e visibilização de suas pautas.

O slam se difere de um sarau, em especial, por incluir o fator de competição, com regras mais estritas para participação (como tempo de apresentação, em geral limitado a três minutos). Além disso, os poemas declamados precisam ser autorais, e suas apresentações não podem ser acompanhadas de instrumentos musicais ou adereços. Já, Eduardo DW, do Slam Clube da Luta, de Belo Horizonte, assim define: "O sarau é o dia a dia, e o slam é a festa" (PACELLI, 2015, não paginado). Como numa festa, não só o artista participa, mas todos os presentes. O público costuma participar ativamente comentando, incentivando, aplaudindo efusivamente e torcendo pelos poetas que se apresentam no palco. Além disso, há uma intensa troca entre quem está no palco e a plateia: a forma oral e informal de apresentação convida e inclui quem queira se inscrever e participar da batalha, ou mesmo quem prefira participar dos movimentos de microfone aberto - que não contam para a competição. Como diz Garcia 
(2013, não paginado): "Para ser um poeta slam, basta um poema de autoria própria, um público e um microfone".

Assim, artista e espectador muitas vezes dialogam, conversam, trocam de papel. Stella (2015, p. 3), baseado nos escritos de Roberta Estrela D'Alva, artista e pesquisadora que trouxe o slam para o Brasil, afirma: "os slams que nasceram como competições se configuram enquanto celebração coletiva, que depende do coletivo para a sua existência, pois se não houver plateia a performance poética acaba por se tornar vazia”. Os poemas apresentados são recebidos por uma plateia que participa vigorosamente, pois tratam de temas e sentimentos que afetam, também vigorosamente, o cotidiano daqueles presentes.

\section{A educação na rua em forma de poesia: o caso do Slam das Minas}

Ao passo que as manifestações culturais foram tomando as ruas e praças, colocando em destaque discursos identitários de jovens periféricos, o espaço escolar viu alterarem-se suas condições sem acompanhá-las com mudanças mais estruturais. Conforme Dayrell (2007, p. 1.116), a partir da década de 1990, a escola "passou a receber um contingente cada vez mais heterogêneo de alunos, marcados pelo contexto de uma sociedade desigual, com altos índices de pobreza e violência". As mudanças passaram a evidenciar a necessidade de renovação de seu espaço e práticas, vez que os novos sujeitos que passaram a ter acesso ao espaço escolar "trazem consigo novas formas de se expressar, de utilizar a linguagem, de produzir conhecimento, de vivenciar e significar o mundo" (SILVA, 2019, p. 82). A esse respeito, diz Gomes (1999, p. 2-3): “É verdade que a partir dos anos 90 a questão das diferenças vem ocupando um outro lugar no discurso pedagógico. Cada vez mais, a escola é impelida a ressignificar sua prática pedagógica de acordo com as profundas mudanças ocorridas nos últimos anos".

Mas, "se a escola se abriu para receber um novo público, ela ainda não se redefiniu internamente, não se reestruturou a ponto de criar pontos de diálogo com os sujeitos e sua realidade" (DAYRELL, 2007, p. 1.117). A escola acaba por não reconhecer esse "jovem" no sujeito "aluno" e tampouco compreende a diversidade (étnica, de gênero ou orientação sexual, entre outras formas) que ele pode apresentar (DAYRELL, 2007).

O objetivo de tal reflexão é entender que a escola é um espaço de constantes desafios a serem superados. Ela é, em si, desafiadora, noção provocada pela percepção de como as propostas da educação não conseguem atingir a diversidade de estudantes que ela comporta. Como afirma Dayrell (1996), existe um discurso de democratização da escola, que acaba por 
desencadear uma perspectiva homogeneizante e que reduz em seus projetos políticos pedagógicos a função da escola a apenas transmitir informações, considerando os conhecimentos como produtos e os sujeitos sociais como meramente alunos.

Assim, por um lado, a escola oferece muitas possibilidades de reflexão sobre diferentes temáticas sociais. Pela diversidade que nela se encontra, configura-se um ambiente que, para além do espaço de estudo, também se amplia para um espaço de sociabilidades, pois é, sobretudo, um espaço que reflete as relações humanas que se estabelecem no ambiente externo, ou seja, a escola não está isolada das contradições presentes na sociedade em que vivemos. Por outro, a escola, por si só, não consegue responder aos desafios da inserção social dos jovens, tendo poder limitado na superação das desigualdades sociais e nos processos de emancipação social. Ademais, a escola tem perdido, segundo Dayrell, “o monopólio cultural, com uma concorrência cada vez maior da cultura de massas e da circulação social de informações" (DUBET apud DAYRELL, 2007, p. 1.117).

Partindo dessas observações é que procuramos identificar nos slams, em especial nos Slams das Minas, que aqui tomamos como exemplo, o quanto podem essas atuações ser identificadas como exercícios não só artísticos, mas também educacionais, e dialogar com processos da educação escolar. Pois, como ressalta Pires (2012, p. 22), "para além dos espaços escolares, o contexto urbano e os processos sociais e culturais do seu cotidiano são também instâncias educativas".

Os slams exclusivamente femininos nomeados em várias partes do país como Slam das Minas, surgiram para propiciar um lugar que as jovens não percebiam nos slams tradicionais. Lima (2016), em matéria do Nexo Jornal, conta, por exemplo, que quando Luz Ribeiro - vencedora da edição de 2016 do campeonato nacional de slams (Slam BR) começou a participar dos slams, ainda em 2012, os homens eram sempre maioria nas batalhas: "Eu me recordo de ser a única mulher em muitas competições, ou de ter só mais uma", diz a poetisa. Assim, completa: "o Slam das Minas surgiu para ser um lugar onde as mulheres se sentissem à vontade para falarem seus textos. Acho que ele recria esse lugar em que a mulher tem direito de fala".

Em outra matéria, para o site I hate Flash, intitulada "Slam das Minas: a revolução feminina através da poesia”, jovens do Slam das Minas do Rio de Janeiro demonstram em seu texto essa angústia pela fala, pelo fazer e ouvir poesia como forma de catarse, de cura, de voz: "Vibramos, choramos, rimos, nos arrepiamos juntas, que é para isso a poesia: para fazer ver" (CAMPOS; TAI, 2017, não paginado). 
Esse processo compartilhado se dá pelo reconhecimento, entre as jovens, das mesmas dores, das mesmas lutas, ou de dores outras que despertam empatia. As autoras afirmam que, ao fim do slam, o fenômeno não se encerra. A vontade de dizer segue, refletida na praça, que agora funciona como ágora para a percepção e assunção de posições políticas e compartilhamento de experiências. O sentimento é de demanda de ainda mais direitos: "Eu quero falar. Eu quero falar. A praça ainda cheia de poesia e dessa energia transformadora de gente que descobriu a própria voz. A revolução já está sendo" (CAMPOS; TAI, 2017, não paginado).

Assim, nas considerações de Sparks e Grochowski (2002, p. 13, tradução nossa):

Como um espaço de possibilidade os slams de poesia também fornecem uma via educativa onde jovens estão tanto ensinando uns aos outros sobre seus mundos da vida como aprendendo sobre a palavra falada ${ }^{5}$ como uma forma de poesia. Eles falam uns com os outros, através de sua poesia, sobre como experienciam suas vidas e como eles vivem suas vidas. Eles falam livremente sobre suas diferenças e o que significa recusar-se a desistir de quem eles são.

Pode ser observada a preocupação coletiva nos espaços produzidos e o quanto os discursos destas mulheres buscam e logram influenciar e impactar outras que vivenciam conflitos sociais semelhantes. O que vem sendo abordado nas competições de poesia são temas que fazem parte do cotidiano e da realidade de muitas mulheres. Compreendemos que por meio dos slams, assuntos como machismo, racismo, feminicídio, violências sexuais e de gênero, lesbo e transfobias e tantos outros temas que afetam as vidas cotidianas de jovens mulheres estão sendo debatidos na rua, em espaços públicos e formando socialmente as/os ouvintes de forma poética, atingindo indivíduos em suas subjetividades. Como ensina Freire (1987, p. 39): "Ninguém educa ninguém, ninguém educa a si mesmo, os homens se educam entre si, mediatizados pelo mundo".

Viana (2018), que analisa slams escolares (batalhas de poesia promovidas dentro do espaço escolar como parte de atividades de ensino de linguagens), aponta que a maior parte dos temas que surgem nos poemas dos alunos não é debatida em seu contexto escolar. Assim, seus discursos mostram "uma lacuna de discussões, de que nossos alunos são privados, ao mesmo tempo em que fazem emergir um posicionamento crítico com relação à realidade social que os cerca" (VIANA, 2018, p. 127).

\footnotetext{
${ }^{5}$ Em inglês, o termo "spoken word" está relacionado a performances de poesia.
} 
A educação, dentro e fora dos muros das escolas, pode e deve ser transformadora, e os slams, promovendo debates de pautas sociais, podem contribuir para esse trabalho. A própria educação, de um modo mais amplo, necessita estar em constante transformação, pois a formação humana é uma relação social em constante construção. Ou seja, é necessário aprender a ensinar e ensinar a aprender de forma dialética, com o outro, para que os próprios indivíduos envolvidos se identifiquem com o processo de aprendizagem.

Ao relacionar a educação escolar e as batalhas de poesia, procuramos nos referir a processos de aprendizagem social que dizem respeito aos conflitos, às formações de sociabilidades, a grupos sociais preocupados em fazer avançar o respeito à diversidade humana, e que muito têm a contribuir para reduzir os efeitos limitantes da educação institucionalizada.

A educação institucionalizada, especialmente nos últimos 150 anos, serviu no seu todo - ao propósito de não só fornecer os conhecimentos e o pessoal necessário à máquina produtiva em expansão do sistema do capital, como também gerar e transmitir um quadro de valores que legitima os interesses dominantes, como se não pudesse haver nenhuma alternativa à gestão da sociedade. (MÉSZÁROS, 2008, p. 35).

Observando os processos construídos nos espaços de batalhas de poesia surgem inúmeras reflexões sobre como as escolas muitas vezes podem servir como inibidoras nesse processo de emancipação mais crítica. Participando dessas batalhas, ao observar como elas se constroem em processos de formação social que avançam no debate e liberação de opressões de raça e gênero, por exemplo, é que nos é colocada a percepção de que outras formas vêm sendo pensadas para criar essas condições de libertação a partir da educação, mas fora do espaço institucional. Nesse caso, elas vêm se desdobrando nas ruas e em forma de poesia. Diz-nos Gomes (1999, p. 4):

Avançar na construção de práticas educativas que contemplem o uno e o múltiplo significa romper com a ideia de homogeneidade e de uniformização que ainda impera no campo educacional. Representa entender a educação para além do seu aspecto institucional e compreendê-la dentro do processo de desenvolvimento humano. Isso nos coloca diante dos diversos espaços sociais em que o educativo acontece e nos convida a extrapolar os muros da escola e a ressignificar a prática educativa, a relação com o conhecimento, o currículo e a comunidade escolar. Coloca-nos também diante do desafio da mudança de valores, de lógicas e de representações sobre o outro, principalmente, aqueles que fazem parte dos grupos historicamente excluídos da sociedade. 
Aponta Freire (1987, p. 35) que "os chamados marginalizados, que são os oprimidos, jamais estiveram fora de. Sempre estiveram dentro de. Dentro da estrutura que os transforma em "seres para outro"”. A solução para eles não está, portanto, em integrar-se a tal estrutura, mantendo o estado de coisas, mas "em transformá-la para que possam fazer-se 'seres para si"”. E, como afirma Dayrell (2007, p. 1.110), para esses jovens "destituídos por experiências sociais que lhes impõem uma identidade subalterna", as atividades culturais "são um dos poucos espaços de construção de uma autoestima, possibilitando-lhes construir identidades positivas". Ainda:

Um exemplo claro é o sentido que os jovens atribuem ao lugar onde vivem. Para eles, a periferia não se reduz a um espaço de carência de equipamentos públicos básicos ou mesmo da violência, ambos reais. Muito menos aparece apenas como o espaço funcional de residência, mas surge como um lugar de interações afetivas e simbólicas, carregado de sentidos. Pode-se ver isso no sentido que atribuem à rua, às praças, aos bares da esquina, que se tornam, como vimos anteriormente, o lugar privilegiado da sociabilidade ou, mesmo, o palco para a expressão da cultura que elaboram, numa reinvenção do espaço. (DAYRELL, 2007, p. 1.112).

Em especial no caso das mulheres, dialogando com Spivak (2010, p. 67), a autora afirma: "Se, no contexto de produção colonial, o sujeito subalterno não tem história e não pode falar, o sujeito subalterno feminino está ainda mais profundamente na obscuridade”. Em um movimento contrário, as jovens mulheres, em especial de comunidades de periferias, encontram formas de dizer de si, no seu próprio trabalho de promover os slams e incentivar a fala, também, de outras mulheres.

Em entrevista a Oliveira, as organizadoras do Slam das Minas de Salvador, Bahia, contam:

\begin{abstract}
Nesse espaço tem mulheres das mais jovens às mais velhas e elas não eram vistas recitando em outros espaços, com autonomia e incentivo, com coragem para chegar no Slam das Minas e dar a ideia, ser a própria voz das vivências. E fora que apesar dos vários empecilhos que encontramos, têm pessoas da comunidade que participam, a gente vê crianças de 10 e 11 anos de idade, da comunidade ou fora dela, recitando poesia autoral. [...] E uma avaliação de felicidade, e muito boa, porque a gente tem um público de mais de 60 mulheres, que estavam reclusas no seu mundo, na sua comunidade. Tivemos uma explosão de mulheres e de grupo (SLAM DAS MINAS, 2017, grifo nosso).
\end{abstract}

Destacamos: "ser a própria voz" de suas vivências, como se afirma nesta fala, é vital, em especial para sujeitos a quem a voz sempre foi negada, silenciada, interrompida. Neste sentido, afirmam Sparks e Grochowski (2002, p. 13-14, tradução nossa): “a linguagem 
testemunhal legitima e torna visível o que foi velado ou invisível na cultura midiática dominante, assim fornecendo conhecimentos alternativos enquanto ao mesmo tempo promovendo maior compreensão da diferença".

Spivak, em seus estudos questionadores sobre a fala subalterna, apoia-se em Foucault: “tornar visível o que não é visto pode também significar uma mudança de nível, dirigindo-se a uma camada de material que, até então, não tinha tido pertinência alguma para a história e que não havia sido reconhecida como tendo qualquer valor moral, estético ou histórico" (FOUCAULT apud SPIVAK, 2010, p. 61). O movimento dessas jovens, organizando-se pela construção de espaços que as permitam o dizer e o serem ouvidas, recria suas existências.

Podemos considerar que a atuação dessas jovens nos slams contribui em sua formação educativa, social e política, podendo as batalhas funcionar como formas de educação popular, com as quais a escola pode e deve dialogar, a fim de se construírem processos educativos mais diversos e emancipadores.

\section{Considerações}

Olhar com sensibilidade para os significados que os slams propõem, os princípios, formas de expressões referentes a conflitos, violências e opressões estruturadas na sociedade, e nos processos de sociabilidade por eles construídos, nos possibilita ir ao encontro da desconstrução ideológica de uma linha de pensamento dominante que produz uma imagem engessada da juventude das classes populares com um discurso baseado nos critérios sociais e raciais bem definidos como sendo determinantes para legitimar a opressão e descrença na juventude, caracterizando-a como violenta e sem um projeto de vida definido. E talvez sejam tais "características" raciais e sociais que tornaram a juventude brasileira historicamente alvo da acusação constante como um elemento altamente perigoso, digno de sofrer represálias, o que torna relevante a compreensão do reflexo desse tipo de pensamento dentro das instituições escolares.

Em contrapartida, pode ser observada nas formações dos slams uma juventude organizada no intuito de promover espaços educativos capazes de contribuir para a formação dos seus coletivos e dos demais indivíduos que se proponham a participar do espaço. Podemos observar a capacidade de influenciar pessoas na promoção de um discurso de liberdade contra a exploração dos corpos, demarcado pelo combate ao racismo, violências de gênero e outras formas de opressão, que vem se comprometendo a educar uma nova geração de pessoas capazes de aprender a lidar melhor com a diversidade que faz parte da própria 
realidade em que convivem. Diversidades essas que são muitas vezes alvos da violência e exploração.

A estrutura que estratifica a sociedade mediante critérios raciais e também de classe coloca especialmente os jovens de periferias em uma situação desigual no que tange ao acesso de oportunidades experimentais e de possibilidades de vivências. Ressalta-se, ainda, o critério de gênero que coloca em situação ainda mais difícil o lugar de jovens mulheres, em especial negras, das periferias. Pode-se dizer que esses grupos de jovens refletem muito bem como uma sociedade sustentada nesses critérios promove relações desiguais de poder e estabelece exclusões quanto ao acesso aos bens artísticos, culturais, educacionais, econômicos e patrimoniais, que atingem diretamente os jovens em formação. No contexto escolar, muitas dessas desigualdades podem ser reproduzidas, ou não haver espaço sólido para que se debruce e discuta sobre elas.

O que se apresenta como perspectiva é a proposta que se materializa em novas formas educativas que contribuem no processo de formação humana e social desses sujeitos. E, principalmente, o reconhecimento desses espaços, que vêm se constituindo nas ruas, como espaços relevantes. Como educadores populares ou formais cabe a nós incentivarmos os jovens a estar inseridos nesses projetos, de modo a influenciar mudanças importantes na forma de ver a educação, inclusive permitindo-nos aprender com esses setores da juventude a como promover uma educação que seja capaz de pensar a diversidade de forma mais positiva - e propositiva.

Esse artigo procurou contribuir na reflexão e debate sobre o slam como manifestação cultural educativa, propondo que ele pode ser considerado como espaço de educação popular não formal. Como novos caminhos possíveis de pesquisa, apontamos o interesse e a necessidade de trabalhos que dialoguem diretamente com os sujeitos envolvidos nos slams, trabalhos de campo que abram espaço para que o texto inclua sua própria voz, ainda que mediada por nós.

Também interessa analisar outras formas de promoção à educação fora dos espaços institucionais escolares, a fim de compreender como processos educativos vêm se desenvolvendo em espaços abertos como a rua, em modos pelos quais não só jovens, mas outros atores sociais vêm se dedicando a reconstruir caminhos que garantam uma formação social e política críticas, frente à necessidade de garantir a liberdade de existir em meio à diversidade de sujeitos que formam a sociedade. Respeitar a diversidade é estar diante de uma luta contra as opressões e explorações à Humanidade. 


\section{Referências}

CAMBRIDGE DICTIONARY. Disponível em:

http://dictionary.cambridge.org/pt/dicionario/ingles/slam. Acesso em: 19 nov. 2019.

CAMPOS, B.; TAI, L. Slam das Minas: a revolução feminina através da poesia. I hate flash.net, Rio de Janeiro, maio 2017. Disponível em: https://ihateflash.net/zine/primeiroslam-das-minas-rio-de-janeiro. Acesso: em 21 nov. 2019.

D’ALVA, R. E. Um microfone na mão e uma ideia na cabeça: o poetry slam entra em cena. Synergies Brésil, França, n. 9, p. 119-126, 2011. Disponível em:

https://gerflint.fr/Base/Bresi19/estrela.pdf. Acesso em: 30 mar. 2019.

DAYRELL, J. T. A escola "faz" as juventudes? Reflexões em torno da socialização juvenil. Educação e Sociedade, Campinas, v. 28, n. 100, Especial, p. 1.105-1.128, out. 2007. Doi: 10.1590/S0101-73302007000300022.

DAYRELL, J. T. A escola como espaço sócio cultural. Educação em Revista, Belo Horizonte, v. 15, p. 21-29, jun. 1996.

FREIRE, P. Pedagogia do oprimido. 17. ed. Rio de Janeiro: Paz e Terra, 1987.

GARCIA, J. Slam Poetry: microfone e poesia. Blog Radio Poesia, Guamaré, 22 out. 2013. Disponível em: http://webradiopoesia.blogspot.com/2013/10/slam-poetry-microfone-epoesia.html. Acesso em: 20 jul. 2017.

GOMES, N. L. Educação e diversidade cultural: refletindo sobre as diferentes presenças na escola. Revista do Museu Antropológico, Goiânia, v. 3 e 4, n.1, p. 9-17, 2000. Disponível em: https://www.sinprodf.org.br/wp-content/uploads/2012/01/educa\%C3\%87\%C3\%83o-ediversidade-cultural.pdf. Acesso em: 16 mar. 2020.

HOLLANDA, H. B. Literatura marginal. 2005. Disponível em:

http://heloisabuarquedehollanda.com.br/literatura-marginal/. Acesso em: 12 jul. 2018.

LIMA, J. D. O que são slams e como eles estão popularizando a poesia. Nexo Jornal, São Paulo, 20 dez. 2016. Disponível em: https://www.nexojornal.com.br/expresso/2016/12/20/Oque-s\%C3\% A3o-slams-e-como-eles-est\%C3\%A3o-popularizando-a-poesia. Acesso em: 24 nov. 2018.

MÉSZÁROS, I. A educação para além do capital. Tradução de Isa Tavares. 2. ed. São Paulo: Boitempo, 2008.

OLIVEIRA, H. Slam das Minas Bahia: poesia negra, periférica e feminina [Entrevista cedida a] REVER On-line, 3 set. 2017. Disponível em: https://reveronline.com/2017/09/03/slamdas-minas-bahia-poesia-negra-periferica-e-feminina/. Acesso em: 13 nov. 2019.

PACELLI, S. Ainda pouco divulgada no Brasil, a poetry slam cresce e conquista público dia a dia. Portal Uai, Belo Horizonte, 13 out. 2015. Disponível em:

https://www.uai.com.br/app/noticia/e-mais/2015/10/13/noticia-e-mais,172835/ainda-poucodivulgada-no-brasil-a-poetry-slam-cresce-e-conquista-publ.shtml. Acesso em: 5 abr. 2019. 
PIRES, E. G. Educação, narrativa e experiência urbana: o aprendizado da cidade. 2012. Tese (Doutorado em Educação) - Programa de Pós-Graduação em Educação, Universidade de Brasília, Brasília, 2012.

SILVA, P. L. Percursos linguageiros nos processos e experiências de letramento de jovens poetas participantes do slam interescolar. 2019. Dissertação (Mestrado em Educação) - Programa de Pós-Graduação em Educação e Formação Humana, Universidade do Estado de Minas Gerais, Belo Horizonte, 2019.

SPARKS, B.; GROCHOWSKI, C. Narratives of youth: cultural critique through spoken word. In: SEMINARIO CIENTIFICO SOBRE LA CALIDAD DE LA EDUCACIÓN. Matanzas, Cuba. 2002. Disponível em: https://files.eric.ed.gov/fulltext/ED474559.pdf. Acesso em: 15 mar. 2020.

SPIVAK, G. C. Pode o subalterno falar? Belo Horizonte: Editora UFMG, 2010.

STELLA, M. G. P. A batalha da poesia... O slam da Guilhermina e os campeonatos de poesia falada em São Paulo. Ponto Urbe, São Paulo, n. 17, 2015. Doi: 10.4000/pontourbe. 2836.

VIANA, L. Poetry slam na escola: embate de vozes entre tradição e resistência. 2018. Dissertação (Mestrado em Letras) - Faculdade de Ciências e Letras, Universidade Estadual Paulista, Assis, 2018.

Submetido em 21 de novembro de 2019. Aprovado em 14 de fevereiro de 2020. 